\title{
Implementing Quality Assurance in Saudi Arabia: A Comparison between the MESO and the MICRO Levels at PSU
}

\author{
Saud Albaqami ${ }^{1,2}$ \\ ${ }^{1}$ Ministry of Higher Education, Riyadh, Saudi Arabia \\ ${ }^{2}$ School of Education, the University of New South Wales, Sydney, Australia \\ Correspondence: Saud Albaqami, School of Education, the University of New South Wales, Sydney, NSW, 2035, \\ Australia. Tel: 61-434-584-629. E-mail: saudsaad5@gmail.com
}

\author{
Received: April 15, 2015 \\ Accepted: May 14, 2015 \\ Online Published: May 25, 2015 \\ doi:10.5539/hes.v5n3p66 \\ URL: http://dx.doi.org/10.5539/hes.v5n3p66
}

\begin{abstract}
Quality assurance in higher education remains to be one of the most prominent fields of research at the present. In the Saudi Arabian higher education institutions (HEIs), quality assurance is a relatively new concept and Saudi universities seem not to effectively implement quality assurance caused by the certain obstacles. As such, there are two objectives to be addressed; first, to explore the current quality assurance mechanisms. Second, to identify factors that enhances or hinder the effectiveness of the internal quality assurance system in Saudi Arabian HEIs. A case study involving Prince Sultan University was used to examine these questions. Data was collected using semi-structured interviews with both meso and micro levels, as well as document analysis and observation. A grounded theory approach based on that advocated by Strauss and Corbin was taken to analysis the data. The findings of this study support the perceived use of many different standards based evaluative processes, which provide feedback from the various stakeholder perspectives. The findings also demonstrate perceived supportive factors of the commitment/support of leadership and management, awareness and orientation of employees/faculty. In addition, the findings also report that/faculty resistance and infrastructure limitations focused on financial and human capital constraints were perceived as inhibitive factors to QA.
\end{abstract}

Keywords: NCAAA, PSU, quality assurance mechanism, factors influencing, the quality assurance implementation

\section{Background of the Study}

In the Saudi Arabian higher education sector, quality assurance is a relatively new concept. The National Commission for Academic Accreditation and Assessment had previously developed a set of Standards for Quality Assurance in Higher Education (NCAAA, 2009). These standards are to be applied to all higher educational programmes in Saudi Arabia, both public and private university (NCAAA, 2009, p. 1). The NCAAA requires that every institution has to create its own quality assurance model. Yet inspire of these new developments, some higher education institutions in Saudi Arabia have yet to develop formal quality assurance systems and failed to implement NCAAA's standards. NCAAA (2012) reported that just 3 universities out of 33 universities were able to be granted a full institutional accreditation. As such, Saudi Arabian higher education universities seem not to effectively implement quality assurance caused by the certain obstacles. In Saudi Arabian setting, there are still no studies conducted on the overall state of higher education quality assurance. The reason behind this gap in literature may be that there are still too few case studies that have been conducted to assess quality assurance practices and experiences in Saudi Arabian higher education institutions specifically with the utilization of institutional theory lens. That is, what remain unexplored are the quality assurance practices and challenges of specific university in Saudi Arabia, which may later on be systematically reviewed to infer the status of quality assurance in the Saudi Arabian higher education system. These considerations bring about the problem that is proposed to be undertaken in this study.

This study intends to determine the extent to which quality assurance mechanisms are currently at PSU and to identify the different factors that influence quality assurance effectiveness in the Saudi Arabian context. Therefore, the research questions of this study are:

(1) What is the current quality assurance mechanism at PSU? 
(2) What are the factors influencing the quality assurance implementation?

\section{Literature Review}

\subsection{Quality Assurance in Higher Education}

According to the American Society for Quality(2011), quality assurance is "the planned and systematic activities implemented in a quality system so that quality requirements for a product or service will be fulfilled". Basically, quality assurance is the collection of activities that an organisation performs to make sure that their outputs pass existing standards held by their customers or other important regulating and accrediting institutions.

According to Charles (2007), the origins of quality assurance in higher education can be traced back to a number of higher education milestones in the Western context. Medieval institutions of learning maintained institutional quality through various means. Guilds were formed by students that prescribed specific regulations that their own professors should follow in holding classes. These regulations aimed to ensure that the welfare of the students as learners was not disregarded. At the same time, professors themselves formed master-guilds which sought to safeguard the quality of teaching. The quality of entire institutions of higher learning was overseen by the government, which granted charters and helped institutions develop their own capacity to review their academic programmes and evaluate the effectiveness of their operations.

The concept and practices of quality assurance has been in existence since the industrial age, in which the mass production of different goods required that there be some mechanisms in place for checking that the each of the goods produced was fit for public consumption (Dill, 2010). However, it was only during the latter half of the $20^{\text {th }}$ century that this concept and its practice found its way to the operation of higher education institutions. (Dill, 2010; Barnabas, 2007)

As explained by Barnabas (2007), the early higher education institutions did have different standards of quality established and did maintain some practices focused on securing such standards. However, quality assurance in higher education as it is known today began with the establishment of governmental and non-governmental agencies that sought to develop and examine different dimensions of quality in higher education institutions and provide corresponding accreditation based on the levels of quality found (Brigham, 2001).

In the United States, the first accrediting institution was established in the 1960's, and was an organization that consisted of different, well-respected, post-secondary institutions that developed a process of peer evaluation (NAPCIS, 2012). In the United Kingdom, the quality movement began in 1992, when Higher Education Quality Councils were established for England, Scotland, and Wales which were given the responsibility to assure quality of higher education institutions within their areas of responsibility (Brennan et al., 1998). These councils were abolished in 1997 and replaced with the Quality Assurance Agency for Higher Education, a non-governmental organization that followed a model of peer-evaluation. (University of Aberdeen, 2012)

In 2000, University Quality Agency (AUQA) was established in Australia state and national governments with the voluntary audit approach. According to (Anderson, Johnson, \& Milligan, 2000), audit by AUQA was required for higher education institutions the access to federal funds. AUQA was replaced with The Tertiary Education Quality and Standards Agency (TEQSA) in 2011. TEQSA is assessing the higher education institutions in reflection to the Higher Education Standards Framework (TEQSA, 2014). Meade (1995) outlined the systematic quality improvement of one Australian university, which included developing a continuous quality-improvement management plan, devolving responsibility for quality advancement to faculties and improving documentation of procedures and outcomes. The systematic review of quality assurance in the Australian higher education system reached different but non-contradictory conclusions, such as that higher education quality assurance are promoted by increase of international competition over higher education student markets (Shah et al., 2011). Consistent with this, Shah et al. (2010) found that quality assurance is most often initiated from top to bottom, but the success of such activities are mainly dependent on how well the top is able to influence the bottom. That is, it is important for higher education administrators to convince stakeholders of lower involvement in quality assurance of the importance of the process in their own perspectives, and motivate them to participate extensively in quality assurance activities.

In Finland, the consolidations of results from different quality assurance case studies have already yielded systematic reviews. Huusko and Ursin (2010) examined how academics in Finland experienced and responded to self-evaluations. The findings showed that external quality assurance may be time consuming and possibly will increase bureaucracy. In the same setting, Haapakorpi (2011) focused on the Finnish higher educational system found that organisational culture and personal motivation played important roles in quality assurance participation of stakeholders. Haapakorpi (2011) also found that flat organisational models are more likely to promote participation of internal stakeholders in quality assurance work. 
In the Saudi Arabian higher education sector, The National Commission for Academic Accreditation and Assessment (NCAAA) was established by the Higher Education Council in 2004 (Almusallam, 2012). The commission was part of the initiative to improve and standardize the quality of higher education in Saudi Arabia. According to the NCAAA (2010), the mission of the organization is "to encourage, support and evaluate the quality of post-secondary institutions and the programs they offer". Specifically, this means that the commission is involved in the fulfilment of three major objectives, which are ensuring the quality of students' learning outcomes, monitoring the efficiency of management and support services provided by higher education institutions, and evaluating the quality and impact of research and community development contributions made by higher education institutions (NCAAA, 2010). These objectives are carried out in cooperation with higher education institutions and in consultation with various external stakeholders, such as community agencies, business companies in various industries, and government (NCAAA, 2010).

Among the tasks that are expected of the NCAAA are to establish quality assurance standards in Saudi Arabian higher education that are consistent with international benchmarks and relevant to Saudi Arabian national interests, to integrate internationally recognised best practices in quality assurance protocols for higher education institutions, to serve as a guide to quality assurance for higher education institutions in Saudi Arabia and provide support to these institutions in developing their own quality assurance systems, and developing a database of best practices and relevant quality indicators for higher education institutions in Saudi Arabia (NCAAA, 2010).

The National Qualifications Framework is an important component in the system of accreditation and quality assurance in the Kingdom of Saudi Arabia. It is designed by NCAAA to ensure that the quality of post-secondary education is equivalent to high international standards (NCAAA, 2006) .The standards for quality assurance that are followed by the NCAAA are detailed in chapter 2 of the Handbook for Quality Assurance and Accreditation (NCAAA, 2012). There are five major contexts of quality assurance considered by the NCAAA (2012), which are the institutional context, the learning and teaching context, the student support context, the supporting infrastructure context, and the community contributions context. Under these groups, there are eleven broad standards identified. According to NCAAA 2012, providing evidence rather than relying on reputations or general impressions the judgment of the quality should be based on.

Reviewing the literature, it was found that in different countries all over the world, studies are being conducted to determine the extent of implementation of quality assurance activities in higher education institutions within such countries and the challenges that the implementation of such activities face in the given contexts. In the Saudi Arabian context, only one general study on quality assurance in higher education was identified. Darandari et al. (2009) discussed how the rapid growth of higher education institutions in Saudi Arabia has generated increased need for quality assurance, prompting the development of the National Commission for Academic Accreditation and Assessment. The study focused on different aspects of the three-stage quality assurance and accreditation system that was constructed by the commission, which according to Darandari et al. (2009) has greatly benefited Saudi Arabian higher education institutions by helping them develop international expertise while still maintaining their cultural identity. In another studies related to quality assurance in the Saudi Arabian higher education system, two studies were found. One of them endeavoured to conduct quality assessment of dental health services in the faculty of dentistry at the university, through the participation of faculty members and dentists who were documented while teaching and conducting procedures (Hassan et al., 2005). The other study focused on the engineering education at King Abdulaziz University (Zahed et al., 2007). This study found that all 12 degree programmes offered by the College of Engineering have been undergoing considerable quality assurance protocols in line with a five-year strategic plan (Zahed et al., 2007). Challenges that were identified by the studies were deficiencies in knowledge of more advanced systems for carrying out quality assurance measures and funding restrictions (Zahed et al., 2007). However, these case studies did not assess quality assurance in the institution, but rather applied quality assurance practices to specific areas in the institution. As such, there has yet to be a study that endeavoured to determine the quality assurance experiences of PSU and the factors that influence the institution in the pursuit of quality assurance goals. To date, this study claims that it is the first study in which institutional theory has been utilised in Saudi Arabian higher education context. This is the specific gap in existing literature that is pursued by this proposed study.

\subsection{Institutional Theory}

This theory is focused on particular aspects of social structures that are inherent in organisations and communities. Specifically, institutional theory delves deeper into the social structure. According to the theory, conformity to the rules. Norms and values of the institutional environment is compulsory for the sake of legitimacy (Meyer \& Rowan, 1977; Covaleski et al., 2003). Organisations enhance the chances of their survival and for the by designing formal structure in accordance with the institutional environment that constitute their 
behaviour (Meyer \& Rowan, 1977; Powell \& DiMaggio, 1991; Oliver, 1997).

DiMaggio and Powell (1983) consolidated inputs on institutional theory from several of its proponents and found that institutions in making a transition between one condition and another consist of three possible mechanisms of isomorphism. Firstly, there is the coercive isomorphism in which the organisation is led to adopt new structures through compulsion such as from the mandate of a law. Secondly, there is mimetic isomorphism in which the organisation follows the lead of another organisation with the purpose of reducing uncertainty (DiMaggio \& Powell, 1983). According to (DiMaggio \& Powell, 1983), the third mechanism is normative isomorphism in which the pressure of seeking the professionalization norm. The organisation adopts the new condition based on the recommendations of experts within the organisation.

Applying the theory, higher education institutions seeking to establish a quality assurance system may do so under one or more those mechanisms. The theory also explains that when an organisation that has been accustomed to operating in one context is suddenly thrust into another, it experiences pressures that exert critical influences on the management of its resources and the conduct of its operations.

From institutional theory, the theory was utilised by studies such as those of Rosa et al. (2006) and Modell (2003) to explain how institutions deal with the development of quality assurance implementation. As discussed by Modell (2003), which is appropriate to this study, investigated the development of quality control measures among Swedish universities, quality assurance is an endeavour that normally challenges the members of institutions into providing evidence that they have been fulfilling their roles and responsibilities properly. It is resisted because it challenges the norms and cultures that people within the institution have been accustomed to, and generates the fear of change affecting both professional and personal lives (Modell, 2003).

Rosa et al. (2006), on the other hand, conducted a study to explore the perception of rectors and academic on quality assessment system at Portuguese universities and their consequence at the institutional level. The authors found that the staff rectors held positive views in implementing quality assurance. Furthermore, they argued that new universities in Portugal were more adaptable in implementing quality assurance.

\section{Methodology}

\subsection{Research Design}

A qualitative research design was selected for this study. As explained by Merriam (1997, p. 5), qualitative research follows an interpretive paradigm, in which the interest is not to test a theory or measure different variables, but to understand a certain phenomenon based on the perspective of the people who experience it. The study seeks to develop a deep understanding of the phenomenon, and draw out findings that are only but distinctively applicable to the groups or institutions investigated, then the qualitative design is more appropriate (London School of Economics, 2012). Among the five traditions of qualitative inquiry (Craswell, 1997), a descriptive case study (Yin, 2009) was ultimately selected as the most appropriate research design for this study.

Through the use of the case study, this research was able to utilise the theoretical frameworks that it established in the review of related literature and consider the application of these to the Saudi Arabian context, particular in the case of PSU. In setting the delimitations of this study, some bounds have been considered. According to Cline (2006), the delimitations of a study are the conscious bounds that capture the scope of its intentions and actions. The first consideration in setting the delimitations of this study is that it is confined to the investigation of single case, which is PSU. As such, this study stays within its capabilities by concentrating on PSU only. The second delimiting bound of this study is that, this study recognises that there are various dimensions of quality assurance that are important in the development of a normative model. However, at the same time, it is considered that constraints related to data security and institutional privacy may prevent the study from gaining access to critical data needed for developing the model for some of the dimensions. As such, this study binds its scope to only one of the dimensions, which is quality assurance in teaching and learning. This was selected because it is one of the traditional pillars in the missions of higher education institutions, and because the study would most likely have access to data that are relevant to those this dimension. Finally, this study acknowledges that there are many perspectives that can be considered when conducting a case study, and that the perspective of every stakeholder in the setting potentially has something significant to add to the understanding of the case. However, as with the dimensions of quality assurance, this study yields to the limitations of its resources in accessing necessary data and delimits the scope of the study to the two groups of stakeholders that are most relevant to the quality assurance dimensions identified. These are the faculty members and the administrative staff. While it may also be insightful to gather data from students, the primary focus of this study was centred on those who are the two groups of stakeholders that were included in the scope of this study.

\subsection{Data Collection}


Documents analysis and semi structured interview with a total of ten university employees were collected in the study. Interviews were conducted to gather relevant data in order to address the research questions of the study. Based on the result of utilizing institutional theory, participants were divided into two groups to compare both the MESO and the MICRO levels' perception. While the deans were treated to be at the MESO level with quality assurance staff, the MICRO level encompasses heads of schools and academic staff. Results specific to each level respectively are situated accordingly and then presented separately for discussion.

\subsection{Data Analysis}

The data analysis began with the development of codes for use in the analysis. The coding stage entailed the coding (or labeling) and categorization of the key responses of participants to the interview questions to reflect the open coding categories, allowing for the codes with similar content to be grouped together (Glaser \& Strauss, 1967). Additional codes were added as necessary throughout the data analysis to represent emerging data concepts. The third stage of the process required the further categorization of the grouped concepts from the previous step, in which the open-coding categories were used to determine the selective coding categories related to the emergent themes of the analysis. The various common selective coding categories represent the perceptions and experiences of the group as a whole (Merriam, 1998; Strauss \& Corbin, 1998). The final step involved a comprehensive review and narrative interpretation of the data to provide the conclusions, or theory, generated from the analysis (Glaser \& Strauss, 1967; Strauss \& Corbin, 1998). NVivo 10® qualitative analysis software was used to assist in the coding and the development of themes and patterns from the data through providing a workspace in which to classify, sort, and arrange the information gathered. From the thematic, selective coding categories and the constant comparing of elements and categories throughout the analysis, several overarching themes were developed.

\section{Results}

\subsection{History}

Prince Sultan University (PSU) is a private university that came into being in 1999 in Riyadh, the capital of Saudi Arabia. The PSU received a license by the Ministry of Higher education as the first private university of the Kingdom (Ministry of Higher Education, 2009).

Eighteen academic programs are offered by the PSU that fall under the domains of College of Computer and Information Sciences, College of Engineering, College of Business Administration and College of Women (PSU, university bulletin, 2013, p. 15) with the total of 288 academic staff of which 244 non Saudi and 46 Saudi graduated from international universes. (Ministry of Higher Education, 2010)

\subsection{Management and Governance}

The regulations of the higher education council are adopted by the PSU for the purpose of management and governance of the university. Since the time the university was established, it has been overseen by the board of trustees, while it has the backing of four committees and council: the Financial Committee, Executive Committee, Internal Auditor and the University Council (psu. edu. sa., 2014).

The University Council President is the Rector, and the members of the Council include the Vice-rectors and deans of Colleges of Engineering, Computer Science and Information Systems, Business Administration, Students Affairs, Admission and Registration, College of Women and Chairperson of Law Department.

There are two Vice-Rectors that aid the Rector: Administrative and Financial Affairs, Academic Affairs and Research. The Vice-Rectors of the Administrative and Financial Affairs look after the Academic Affairs and Research, which involves the areas of Research and Publication, Centre of Community Services and Continuing Education, Library, Computer Centre and Recruitment and Coop. On the other hand, the Vice-Rectors of Academic Affairs and Research look after the Accounts Department, Personnel Department, Communication and Employees Club, Public Relationship Department, Maintenance and Services, Stores and Purchases, Resource Department and Housing Department.

Unlike the majority of Saudi universities, students at PSU have a voice in the governance of university as the University Student Council (USC) is the official body or the biggest governing organization for all certified students of the University. The USC provides a platform for the PSU students to be a part of the University management and is considered to be the official representative body of the students of the PSU. It allows the students to express their point of views freely and candidly to the USC officials who make sure that a suitable follow-up is provided if required. The officers of the Council are chosen by student representatives who are council officers of various departments of the University. 


\subsection{Quality Assurance Arrangement}

The University responded to external pressure from the NCAAA which led to a drastic restructuring in organizational management. The restructuring involved creating quality assurance committees as well as organizational positions that had certain roles and responsibilities.

In 2005, Academic Assessment and Planning Centre (AAPC) was created (PSU: Strategic Plan, 2011). The Director who directly reports to the University Rector supervises the Centre activities.

The AAPC director also manages and nominates members of three committees; The Quality Assurance \& Improvement Committee (QAIC), The Institutional Planning Committee (IPC), and The Assessment and Statistical Committee (ASC). The members of the three committees belong to different academic and administrative departments of the university and are appointed by the University Rector each year. (PSU, AAPC, 2006, p. 7)

The AAPC receives assistance from the Quality Assurance \& Improvement Committee (QAIC) regarding the adoption, supervision and analysis of quality academic and administrative processes of the university. (PSU, AAPC, 2006, p. 7)

In recent times, the PSU quality assurance management has been re-organized with the appointment of Vice-Rector for Quality and development. In addition, the Teaching and Learning Centre (TLC) was also established 2012. The TLC-PSU has the objective of making sure that the faculty members and teaching assistants demonstrate a professional commitment and establish an excellent teaching environment at the University. (psu. edu. sa., 2014)

The TLC Steering Committee (TLC-SC) was the key organisational committee responsible for analysing and monitoring Learning and Teaching Quality Review and Improvement process as the top of the pyramid for teaching and learning quality framework (LTQF) in PSU. This committee was under the supervision of Academic Council (PSU, LTF., p. 5). At the department level, the L \& T Quality Assurance is applied by the Program Quality Assessment Committee (PQAC) in coordination with the AAPC. They report to the AAPC on a regular basis which then regularly reports to the TLC-SC.

\subsubsection{Strategic Plan}

In 2005, the appointment of a new university rector saw the establishment of the first strategic plan in PSU. The Academic Assessment \& Planning Centre (AAPC) was established in September, 2005, which was one year after the creation of NCAAA which led to a drastic restructuring in organizational management at PSU. The restructuring involved creating quality assurance committees as well as organizational positions that had certain roles and responsibilities.

The AAPC director manages and nominates members of three committees; The Quality Assurance \& Improvement Committee (QAIC), The Institutional Planning Committee (IPC), and The Assessment and Statistical Committee (ASC). The members of the three committees belong to different academic and administrative departments of the university and are appointed by the University Rector each year (PSU, AAPC, 2006, p. 7). The AAPC receives assistance from the Quality Assurance \& Improvement Committee (QAIC) regarding the adoption, supervision and analysis of quality academic and administrative processes of the university (PSU, AAPC, 2006, p. 7). The Assessment and Statistical Committee (ASC) is responsible for the evaluation of the academic and organizational units' results and the development of a database of university-wide operations. In addition, it is also responsible for the analysis and reporting of the assessment outcomes. (PSU, AAPC, 2006, p. 7)

The first step of PSU' Strategic Plan is to take into account the vision and mission of the institution. In the planning activity of the PSU, fifty five members took part, including administration officers, academic staff and administrative officials. Subsequently, six groups comprising of 7-9 members were created to review the vision and mission statement of PSU. The vision of the university clearly set out the importance of quality:

"Prince Sultan University was aiming to turn into the leading private university in the Middle East, providing a quality education comparable to other universities in the world" (PSU, Strategic Plan, .p5).

In the second plan, the university moved towards six strategic aims, under the title LEADER. This represented: Learning and Teaching, Effective and Efficient Faculty, Student \& Personnel Management System, Accountability, Diverse Educational resources and facilities, Economic Sustainability and Research and community involvement (PSU, Five-Year strategic plan, 2012, p. 5). The major performance indicators presented by the NCAAA are incorporated in the second plan. The design of 20 strategic goals follows after the strategic 
themes. These goals are defined by 59 objectives, with action plans supporting these objectives (PSU, Five-Year strategic plan, 2012, p. 7).

According to (PSU, AAPC, 2), the views of the constituencies, stakeholders, faculty, students, employers and other relevant parties have been taken into account. Different tools in implementing quality assurance have been used are Course exit surveys, Course Portfolios, Employer surveys, Alumni Survey and Rubrics. According to (PSU, AAPC, 2), the major dimensions of the quality assurance system encompassing; Curriculum Development and Review Process, Academic Assessment Process, Students Assessment Policy, Early Academic Support Policy and Quality Assessment Tools.

\subsubsection{Curriculum Development and Review Process}

The PSU policy specifies that two types of current programs reviews and development are present: minor reviews and major reviews. The purpose of minor review is to ensure correct updating and delivery of course materials. Such a review is informally performed at the department level (PSU. LTQF.). After every three years, major reviews are performed and are based on the collected and monitored information and feedback about the existing program from stakeholders and associated organisations. It is the responsibility of the academic council to take action and suitable decision to confirm any new program design or a major program change after a series of processes. In order to obtain information and feedback from stakeholders, different approaches can be used by the curriculum review committee of each department. A formal procedure is required to obtain approval from the curriculum review committee, college council, department council, and with the opinions of at least two external reviewers. The academic council takes the decision and informs the respective department (PSU. LTQF.).

Even for new programs, a feasibility document is required that indicates the need for the new program and its significance. When the program is approved by the department and the college councils, the same process that is applied for major change in program is followed with additional design process. This includes survey of current and related programs at local and global levels; identifying the courses offered, pedagogy and evaluation approaches, best practices in the program structure, develop the structure of the new program and seek approval from the department and college councils, form the detailed contents of the course, and establish a complete document that includes description of the new program (PSU. LTQF.). The final program is based on the program structure. As per (PSU. LTQF., p. 10), the new programs structure comprises of: Introduction, Program Needs Analysis, Program Objectives, List of Courses, Course Descriptions, Degree Plan, Program requirements, Program Learning Outcomes and Preliminary implementation Plan (PSU. LTQF.).

\subsubsection{Assessment Process}

Each year, a Program Level Quality Committee (PQAC) and course groups for the major program areas is created by the department. It is the responsibility of the PQAC to implement the assessment process. According to (PSU. LTQF.), when the semester commences, a detailed Program Level Quality Assessment Plans (PQA's) is prepared by the PQAC's in all the academic units and departments so that quality of Learning and Teaching in all programs could be monitored and evaluated. To assess the satisfaction of learning outcomes, all the suitable tools and approaches could be applied by the departments. A reasonable standard scale is the basis of such assessment (PSU. LTQF.). The respective Department/Unit Councils are responsible for the PQA's approval. Endorsement of PQA and synchronization of activities occurs at the university level LTC after the approval takes place (PSU. LTQF.).

With the use of surveys and other suitable tools, the program level quality committees are required to gather and review the LT assessment data. This happens at the end of each semester. Based on the results extracted from analysis of the data, recommendations for the good practices promotions or improvements are brought forward by the PQC in detail. The activity is carried out in coordination with the program course groups.

The LTC is responsible for the approval and endorsement of the recommendations as well as the assessment data that has been collected. By analysing the recommendations, summarizing the issues as well as the observations and recommendations, the LTC is able to present an action report to the Academic Council. This Academic Council is now responsible for reviewing the report along with the recommendations in order to carry out the desired action. The PQAC is informed about the decision of the Academic Council by the LTC who also helps them implement the desired actions. (PSU. LTQF.).

\subsubsection{Students Assessment Policy (SAP)}

Encouragement and facilitation of the students learning experience is the objective of the PSU assessment policy. According to (PSU. LTQF, 2014) the assessment should be focuses on learning outcomes, the assessment tasks and practices must include analysing the desired skills, competencies and knowledge. 


\subsubsection{Early Academic Support Policy}

A member of PSU LTQF is The Early Academic Support policy. It entails that during the course of stay of the student with the University, student would be assigned an Advisor. This requirement is part of the Advisory program presented by the PSU. This program helps the teacher to work in an integrated manner with the Advisors to manage students through their absences or academic issues. When a student joins the university, it is commonly observed that he requires help through his academic life. The Teaching \& Learning systems have an objective to provide a strong, well defined student support system. The purpose of this policy is to bring forward a mechanism which consists of an early alert as well as the ability to maximize the benefits. (PSU. LTQF.).Each semester, the students must receive an advising clearance from their academic advisor.

\subsubsection{Quality Assessment Tools}

Evaluation of the program and course learning outcomes needs to be done using several tools as suggested by the departments. The views of the stakeholders, faculty, students, employers and other relevant parties must be taken into account. According to (PSU, AAPC, 2012), tools which may be used are the following: Course exit surveys, Course Portfolios, Employer surveys, Alumni Survey: alumni, Rubrics and Course Portfolio. For each and every course, a course portfolio would be maintained. This information would be used by the course teacher to determine the level of achievement within each course.

\subsection{Understandings and Experiences of Key QA Actors at PSU}

Through the process of the data analysis, common relevant responses, statements, or expressed perceptions or thoughts of the participants were coded and documented. These codlings were then categorized into related sub categories.

\subsubsection{Quality Assurance Mechanisms}

The first thematic category revealed in the data analysis included participant responses related to quality assurance practices. This thematic category was formed from three sub-categories: major processes of quality assurance, mechanisms for evaluating teaching and who is involved in quality assurance formation and implementation. The result in this regards. Each of these sub-categories is discussed separately.

\subsubsection{Major Processes of Quality Assurance}

1) The meso level

The participants commented on the clarity of different processes used by different actors in order to receive feedback from the different perspectives (students, faculty \& administration). For example: participant PSU. V. C1. Explained:

I guess there are a lot of major processes in the university in terms of registering the students... So that's the process involved in the admission and registration. And also we have the personnel office, so all the records of the teaching staff and non-teaching staff are there. So they manage the records for the personnel and teaching and the benefits-everything from housing to insurance, et cetera. And then of course, we have the library. So the library manages the books. And then we have the ITCS, the Information Technology Computer Services, and so all the IT infrastructure. They are the ones who are in charge with that. And then we have the administrative and financial affairs for those matters. Then we have the academic services wherein all the academic departments are managed. And we have the research of course...producing the inter-scholastic output of the university. (PSU. V. C1)

Participants also commonly referred to the continuous and cyclical pattern of the planning and review cycle. This type of planning, implementation, and review cycle has been evident in the examples given thus far, demonstrating implementation of assessments, planning according to feedback, and reviewing the learning outcomes, and developing long term goals and plans. Participant PSU. QM2 described how this process describes the mechanism of quality assurance; for quality assurance. Here, we are following [a] planning and review cycle. So for one, there's a five-year plan. But there's also yearly plan. Planning, monitoring, then action, and then review. (PSU. QM2)

One way of tracking the results of these multiple assessments is through the development of a statistical database. This was described by several participants as contributing to the quality assurance process. According to PSUD2, We generate database for the university making sure that our statistics are updated in terms of number of students, number of graduates, how many are in a six-month period and how many-what is the percentage of our graduates getting employed in the six months after graduation. All these basic statistics for the university, it's our office that generates these. (PSU. D2) 
Continuous assessments are also used to support continuous internal improvement. This was supported and described by participant PSU. QM1, numerous mechanisms have been taken for quality assurance. ...benchmarking is something that we do on a regular basis. We do it for sake of internal improvement, and we also do it because it's also requirement of accreditation purpose. ...one thing is continual improvement, which means that we keep watching, I mean where things are not going good like that and uh where improvement is needed. And we keep incorporating them. Accreditation requires us to do both types of benchmarking - that's local and international. And so we do benchmarking both at local and international. We compare ourselves with the local universities..., and at the same time, we also compare ourselves with [international] universities. (PSU.QM1)

The importance of the database in managing the multiple sources of data, how it is used, and is connected with accreditation was mentioned by PSU. QM2who described:

The University has a uni-[the] AAAPC, which is Accreditation and Assist unit. And this unit has [the staff] who actually help us in getting statistics and getting the data for different [programs] in university and providing data warehouse centre, collecting all this data and we-every time we need some data, we contact them. So the university [is] making this centre body as a service to the rest of the university. So this is a very important role that helping us in the in NCAAA (PSU.QM2).

2) The micro level

In seeking accreditation, the university programs were noted to necessarily identify and reach expected standards. A head of school described:

Actually, we are working on the accreditation, since there is a new system now in Saudi Arabia. The Ministry of Higher Education has a new defined body, which is called National Committee on Academic Assessment and Quality Assurance, NCAAA. So based on that, they have identified those certain standards and them-each university-is expected-each program is expected to use those standards. So we are trying to meet those standards (PSU. HS1).

Along with seeking accreditation, and perhaps as a result of accreditation, an attempt to meet standards is based on to the use of Self-evaluation as stated by participant PSU.TCH3:

We also have this called self-study review. So the self-study review is our internal process of checking our performance-if we are really in good shape or not good shape. So we-but our internal process, we also use the instrument provided by the NCAAA. So this is uh-this is what you call the self-evaluation scales. And we rate it ourselves so-internally. So we have to check (PSU. TCH3).

Another mechanism or mentioned by an academic who discussed the role of benchmarking in continuous assessment, and accreditation standards utilized by AAPC:

Indeed uh there is a whole mechanism for benchmarking... AAPC, we have here separate department that's for the quality assurance and performance assessment mechanism. They have a database for benchmarking. (PSU. TCH1)

Performance indicators review was mentioned as a major process of quality assurance. A head of school described:

Of course, we make a comprehensive assessment. Every month, we have [a] meeting. And in that meeting, we discuss the issues. So in those meetings, problems are reviewed and that's the main responsibility of management - to make sure that when problems happen, they are reviewed. So regarding management indicators, these are the things that we do (PSU. HSO2).

\subsubsection{Mechanisms for Evaluating Teaching}

1) The meso level

When attempting to measure quality at the university, participant PSUQM2described the use of NCAAA guidelines and standards, offering performance indicators to assess quality in the university:

In terms of quality measurement, we follow some guidelines from the NCAAA-the 11 standards. And at the same time, they provided us the KPI-the 36 key performance indicators. They provided us from-from teaching and learning up to research. So they provided us uh key performance indicators. They provided the KPI so that within the kingdom, we can get or they can benchmark, a formal pattern of data to be gathered. And then-so other than that, the university also has our own KPIs to measure the quality performance (PSUQM2). 
Participant PSUD2 described the process as it relates to learning outcomes and the hierarchy of the assessment and interrelatedness of the learning outcome data.

In the teaching and learning, we are measuring the learning outcomes. So for each program, we have program learning outcomes and then to support the program learning outcomes, we have the course learning outcomes. These course learning outcomes support the program learning outcomes. And the program learning outcomes is based on the vision and mission of the college. And the vision and mission is based on the vision and mission of the university. So this is a hierarchy. (PSU D2)

Participants noted the use of a course evaluation, the program evaluation, and the student evaluation surveys. This was evident in two other accounts as well. These included the following responses in terms of internal performance process, For example,

In teaching and learning, if our teacher are really working or really doing their part. So there is a scale there from one to five so five is the highest and one is the lowest. So that's around 300 plus items that we are checking (PSU. D1). In addition to different assessments used to obtain a varied participant response, for teaching... for us, we are using three evaluations from the NC-triple A: the CES course evaluation, the program evaluation, and the student evaluation surveys. (PSU. QM2)

Assessment feedback from different sources (faculty, students and staff) are reportedly used to identify gaps or limitations and to modify the curriculum.

We gather that information and inculcate into our curriculum. We change that curriculum based on the feedback-what we get to make current curriculum. So this is like what we are-three practices out there. One is from graduating student, one goes [to the] employer, and third is the faculty members. We ask, what are the gaps and limitations out there and what are the shortcomings out there among the students and we try to [address] and fill them. (PSU. TCH1)

For example, one participant explained this feedback loop that served to support the formation of program curriculum:

We have already designed a program curriculum. And as I mentioned earlier, that's based on past stakeholder feedback. So that was something that was done earlier. But we keep improving them and benchmarking is something that we do on a regular basis. We do it for the sake of internal improvement, and we also do it because it's also a requirement of accreditation purpose... (PSU. TCH02).

2) The micro level

The use of different feedbacks methods has been confirmed by many participants at the Micro level. PSUH. S2 explained the different informal, rather than formal assessment methods and how the different sources of information are used to support quality assurance:

This is not very formal method... The faculty members' opinions are taken, the students' informal opinions are taken. There is sometimes meeting arranged between the students and director, a meeting arranged between the dean and the students, a meeting arranged between the chairs and the students. So these are all opportunities for them to give their feedback, right? All these are being used for quality assurance purpose. (PSU. H. S2)

These different QA assessments were described as surveys taken by the different stakeholders, students, faculty, and other staff, even alumni, all with the purpose, as mentioned by the previous example, to provide different feedback and to improve quality:

We rely on surveys. We have student evaluation surveys. We rely on faculty evaluation surveys. We have program evaluation surveys. We have alumni surveys. We have employer surveys. You know, we have meetings with employers and the alumni to get the feedback, so all possible efforts are [made] to improve the quality. (PSU. H. S1)

As was found with the overall mechanisms for achieving quality assurance, a common theme with regard to assessing teachers was this use of different types of mechanisms for assessing practice. On participant described this concept in detail, saying:

We have three different types of mechanisms out there or three types of practices out there. First of all, like we get the feedback from the students-informal student-informal feedback. Because customers are our students and customers are our market as well. What we do-we do survey every year. (TCH01PSU) 
Feedback from employer, graduates and professors was used as measurement for curriculum development.

We get feedback from those students who are graduating and going into the market sector. We ask them to give feedback about our curriculum. Then what we do, we ask-we interview our employers-potential employers to ask them how they find our graduates. We do surveys. And what we do, we get feedback. And third, what we do, like we get feedback from professors as well. (TCH03PSU)

Another response offered by head of school was that of the use of quality indicators, and typically, several types of indicators. Using the following example from the text of the interview with Participant PSU. H. S1, this participant provided a lengthy discussion on the several different types of indicators including the ratio of class and the quality of staff as he stated:

We use several types of indicators. Uh so for instance, um one indicator is student to staff ratio. As I said earlier, we are around 20-we have such a proportion that there are 20 students for each of our faculty member... That's one thing. Second thing, um all people here that are qualified here so we make sure that uh only those competent people, uh they are allocated the subjects.

Even though he confirmed the variety of sources of data obtained, in uncommon response he stated the different types of quality measurements including conventional assessment such as exams, assignment and class participation, but the connection to learning outcomes and quality measurement:

We make sure whether students are learning or not... We make evaluation using different types of methods, for instance, we have a conventional assessment method like exams, assignments, uh class participation, uh and then a formal discussion, a project, et cetera. So the second indicator is-what we are looking for is to make sure that leveling takes place..., they are taking some actions regarding program design and delivery. (PSU. H. 1)

4.4.1.3 Stakeholders Involved in Formulation and Implementation

1) The meso level

The key themes within this thematic category were that all or multiple stakeholders were reportedly involved in formulation, assessment, and implementation of quality assurance. This was noted by Participant PSU. V. C1, who stated,

"We strive to let everyone be part of the quality assurance from the staff, from the higher management to teachers to staff to students. Everyone's involved. It's a team effort for the whole university". (PSU. V. C1)

Steering committee representing different level of involvement in the formulation and the implementation through departments to institutional level was noted. For example a quality manager explained:

We have the steering committee members, which include the Rector, the Vice Rectors, the deans and some selected chairs and faculty members. So that is the steering committee. So this is steering committee-also by the-our department head. But-by the way, our department-there's a counterpart of our department head. (PSU. QM2)

Another example is provided by another quality manager who stated:

For each program, we have um program accreditation committee so this program accreditation committee, they are the one in charge per department, per program. So they are the one who manages the quality for their program so it consists of three to five faculty members. So this is additional task for them so this is uh-because AAPC support the institution so we can-because we don't have expertise for each program so our strategy is to-each department should come up with their committee members so they're the one who is managing the quality for their program. So it's very important that there is a staff-teaching staff that will be involved in quality assurance (QM1).

2) The micro level

Many participants at the MICRO level noted that stakeholders are involved through the formation of committees and within their respective departments. The role of the quality committee, as explained by the following participant, is to assure that quality is "driven" through participating in a process of implementation and review. a participant stated:

Generally there are committees out there. There are centers out there like, for example, College of Business Administration; we have a quality assurance department. They are assuring that the quality 
is being driven. Quality is being given to the-to the students and students, they are getting the right quality of knowledge. And what we do, like last term, we did a kind of practice in which we have that committee-quality committee, what they do, they review. (PSU. TCH1)

Participant head of school expanded on this concept of multiple stakeholder involvement, noting that the inclusion of employers in the assessment process was uncertain at first, with the university participants unsure of the cooperation of the employers. This participant stated:

Interestingly, we were a bit hesitant initially to involve the employers in our assessment process, because we don't have any control on them-how far they will cooperate with us. But when we tried-amazing cooperation we got... So by and large, the cooperation was wonderful. Management supports us. Students cooperate with us (PSU. H. S. 1).

A successful cooperation across university was occurred according to an academic (PLSU: TCH3) who emphasized that the involvement of everybody at the university as he stated that:

We are involved. If I would know this thing-that-like this one so we are involved in all this-like I said the workshops were conducted. Faculty was involved in that. Feedback was given. And then implementation comes, all are involved. One person, one team cannot achieve this kind of a target. All the staff-not teachers, but our secretary and staff, they were involved because it's the quality. And quality is for everyone. It's not for like one department. Quality means the process. Everyone should be involved in it. So staff was fully involved. (PLSU. TCH 3)

Factors that Influence the Quality Assurance Implementation: The second major thematic category was developed from participant responses related to specific factors perceived to support or inhibit the implementation of quality assurance at the university. Thus, these sub-thematic categories were revealed from the data, reflective of supportive factors and hindering factors. Each is discussed individually.

\subsubsection{Factors that Support Implementation and Enhance QA}

1)The meso level

This first sub-category was developed from responses related to perceived elements that support implementation and/or enhance the quality assurance process.

The key theme highlights the importance of management and leadership attitude and support in the quality assurance process and the essential factor supporting its success. Participant PSU. QM1 explained:

There are several factors to me that were, more or less, I would say make it [QA] succeed, one of which is the support from top management. And since we started in 2005, the full support of the AAPC received from top management is almost 100\%. We are fully supported. We are fully funded. And that's one [of] the strengths why quality assurance in [this university] is, I would say, successful. (PSU. QM1)

Another factor perceived to support implementation and development of quality assurance is the awareness and orientation of the faculty. When the faculty know what to expect, there was felt to be fewer problems. Participant PSU. D1 stated:

With the implementation, I think it's just [that] we need to be consistent to that every time that we do a certain process, they [faculty] won't be surprised in what we are doing. They would actively know what we are doing. And with that knowledge, they will be more accepting. Make them aware. So sometimes at the beginning of the semester or especially for now we have orientations of new faculty. We already tell them of what to expect, of what the documents we need from them, or that from time to time, we will be going to their classes to conduct surveys or to ask certain documents from them. So if they know this first hand, they will be expecting it and when the time comes for us to do that, there won't be many problems. (PSU. D1)

As a final common factor cited by participants as critical to supporting the formulation and implementation process of quality assurance, participants noted the importance of having a quality culture within the organization. Indeed, achieving a "quality culture" was felt to be a major goal for the organization, as noted by Participant PSU. V. C1, who stated,

"The quality culture has been achieved and that's one of our major objectives-making sure that everyone is conscious and aware of what quality assurance is all about" (PSU. V. C1).

2) At the micro level 
The importance of the role of leadership and management was also highlighted by Participant PSU. H. S1, who stated:

The guy at the top, right, is [the] president, our director of the university. He cares so much about quality, its higher quality. Providing really high quality education. He provides all possible means and ways to ensure that there is quality. (PSU. H. S1)

Quality awareness is an important factor influencing quality implementation. One of the ways to support this type of awareness among the faculty is through orientation. This was explained specifically by one participant, who described the importance of such orientation to all stakeholders, not only faculty members:

The faculty members should be given very good orientation, not only [for] faculty members, [but] as well as possibly almost all the stakeholders, particularly the major stakeholders like students, faculty, and management. They should be given clear orientation as to what kind of a quality system that you want to implement. (PSU. TCH4)

Another commonly cited factor supporting quality assurance is having motivated and supportive faculty, fully participating in the culture of quality at the university. For example, this was suggested by the following participant:

I would say the only main thing is faculty. That's the most important thing in the implementation of quality assurance-the faculty. They are familiar with quality assurance. They know about quality assurance. [When] they understand its importance, then you have no problem. Then what you need to do, you provide some support to them. So every type of support, for instance, resources, et cetera. Not only over here, but [at] almost all universities that have people-people that come from other universities, um then they are motivated about this. They understand this thing. And uh that's the main thing that currently works to quality assurance (PSU. H. S2).

Finally, as a last example, Participant PSU. THC2 offered a detailed explanation of his thoughts on quality culture, what it is, and how it affects the organization:

One major thing is a quality culture. A quality culture means everyone should have a feeling in them or a majority-there will be always exceptions, but a majority should have a feeling that it's-what we want to achieve is something better than what we are-what we have achieved. You know this kind of a spirit.

4.4.2.2 Factors that Inhibit and Hinder the Quality Assurance Implementation

1) The meso level

The second sub-category was formed from the participant responses related to the perceived factors that prevent or inhibit implementation and hinder quality assurance.

Participant PSU. V. C1 noted,

"By and large there is a general resistance in every organization I believe. There is a general resistance from the part of faculty". ( PSU.V.C1)

To further demonstrate the notion of faculty resistance, why it happens, and the associated negative effect on quality assurance processes, the following two examples are provided:

Sometimes, you know, people are afraid of change. And sometimes even if the change [is good]-they don't know that it will be beneficial for them. They just resist it because sometimes change-it means that they would be doing more work and they already, as I said earlier, they [are] already complacent with what they're doing. They don't want any improvement. They just-they're comfortable with the place that they're in. (PSU. QM2)

Some faculty members, although we have established a culture of quality assurance, of course, some faculty members need to understand the process of change. Change will have to be gradual. It doesn't have to be drastic. Each one of-each one should fully support the quality mechanisms for the institutions so that quality assurance will be successful (PSU. QM1).

2)The micro level

Participant PSU. TCH4 described the limitations that were perceived as related to being a small university with limited resources. This participant described:

The hindrance is coming from-I keep on saying this-having said this thing-that we are small 
university and small university have less resources. So this could be one of the hindrance like resources are not utilized on a-on a proper-where it is required. It is not required on the floors. It is not required on the buildings. It should be required on-should be like invested on people-on-Investment on individuals-those who are making it... We are small university doing many things, right? A lot of like the paperwork is there. And doing a lot of workload is there (PSU. TCH04).

Similarly, another participant, PSU. H. S2, described the resource limitations of the school, highlighting financial constraints, which he perceived to delay implementation. And one of the major things, especially in the public domain or public institutions, the financial resources would be very much centralized. And that's where the delay would set in. Delay in terms of implementation because there is so much bureaucracy in terms of approval of budget, for example. Let's say expansion of facilities or buying some equipment for learning and teaching. And that's one of the major concerns. (PSU. H. S2)

\section{Discussion}

The data revealed from the policy analysis and the participants' perspective indicted that quality assurance has been structured and also adequately implemented at PSU. The major performance indicators were constructively conformed to NCAAA standards which raised staff awareness and in turn effect the implementation. This finds is support Carole (2003, p. 298) argument that the more particular the standards, the more specific the outcome that can be anticipated as a result of compliance (Carole, 2003, p. 298).

Alongside with the clarity of the process, a central finding form the analysis is that participants shared distinct understandings of quality assurance mechanisms indicating significant consistency between written internal quality assurance arrangements and the actual practices. Establishing strong quality assurance protocols can be a signifying of value in raising employee motivation and morale. If people in the institution are made aware of the institution's commitment towards maintaining high standards of quality, they will work to the best of their abilities in order to help the institution remain consistent with those standards (Brown, 2011).

The data revealed the use of departments and committees to support the inclusion of all or multiple stakeholders involved in formation and implementation and the successful cooperation across stakeholders. Such involvement is also crucial factors that enhance quality assurance implementation.

The findings also demonstrate perceived supportive factors of the commitment/support of leadership and management which is proved to play a crucial role in the implementing quality assurance. This finding is corresponding with findings of (Csizmadia, Enders, \& Westerheijden, 2008). Awareness and orientation of employees/faculty was also found as important factors to support motivation and quality organizational culture. In addition, the findings also report that/faculty resistance and infrastructure limitations focused on financial and human capital constraints were perceived as inhibitive factors to QA. The comparison between meson and micro revealed that quality assurance implementation remain culture (Harvey \& Stensaker, 2008). This has been brought to the fore by the finding of this research which reveals that the background and the qualification of staff is planning crucial role in implementing quality assurance.

Finally, the study found that the type of the university as a private university may play a significant role in implementing quality assurance as a result of seeking legitimacy which support institutional theory .The age of the university is also found crucial as PSU is considered as relatively new, this is consistent with the argument that new universities have a more positive view of the self-evaluation process and consequently more adaptable in compliance with the external demand (Rosa et al., 2006).

These overarching themes and corresponding perceptions provide the overall conclusions of the qualitative data analysis and are used to address the research questions of the study.

\section{Acknowledgements}

This study is a case study of my PhD thesis untitled "quality assurance in Saudi Arabian Higher Education".

\section{References}

American Society for Quality. (2011). Quality Assurance and Quality Control. Retrieved March 15, 2012, from http://asq.org/learn-about-quality/quality-assurance-quality-control/overview/overview.html

Anderson, D., Johnson, R., \& Milligan, B. (2000). Quality assurance and accreditation in Australian higher education: An assessment of Australian and international practice. Canberra: DETYA.

Brown, S. (2011). Bringing about Positive Change in the Higher Education Student Experience: A Case Study. Quality Assurance in Education: An International Perspective, 19(3), 195-207. http://dx.doi.org/10.1108/ 
09684881111158027

Charles, C. B. (2007). The Evolution of Quality Assurance in Higher Education. Faculty Working Papers from the School of Education.

Creswell, J. (1997). Qualitative Inquiry and Research Design: Choosing among Five Traditions. Sage Publications.

Csizmadia, T., Enders, J., \& Westerheijden, D. (2008). Quality Management in Hungarian Higher Education: Organizational responses to governmental policy. Higher Education, 56(4), 439-455.

Darandari, E. Z., AL-Qahtani, S. A., Allen, I. D., AL-Yafi, W. A., Al-Sudairi, A. A., \& Catapang, J. (2009). The quality assurance system for post-secondary education in Saudi Arabia: A comprehensive, developmental and unified approach. Quality in Higher Education, 15(1), 39-50.

Dill, D. (2010). Quality Assurance in Higher Education-Practices and Issues. International Encyclopedia of Education, 377-383.

DiMaggio, P. J., \& Powell, W. W. (1983). The iron cage revisited: Institutional isomorphism and collective rationality in organizational fields. American Sociological Review, 48(2), 147-160.

DiMaggio, P. J., \& Powell, W. W. (1991). Introduction. In W. W. Powell, \& P. J. DiMaggio (Eds.), The New Institutionalism in Organizational Analysis. Chicago: University of Chicago Press.

Glaser, B., \& Strauss, A. (1967). The Discovery of Grounded Theory: Strategies for Qualitative Research. Aldine.

Haapakorpi, A. (2011). Quality assurance processes in Finnish universities: Direct and indirect outcomes and organisational conditions. Quality in Higher Education, 17(1), 69-81.

Harvey, L., \& Stensaker, B. (2008). Quality Culture: Understandings, boundaries and linkages. European Journal of Education, 43(4), 427-442.

Hassan, A., Amer, H., Abdulbamaid, A., \& Maghrabi, A. (2005). Quality Assessment of Dental Health Services Provided at the Faculty of Dentistry. King Abdulaziz University. Retrieved May 20, 2012, from http://www.kau.edu.sa/Files/165/Researches/591_Quality\%20Assessment\%20of\%20Dental

Huusko, M., \& Ursin, J. (2010). Why (not) assess? Views from the academic departments of Finnish universities. Assessment and Evaluation in Higher Education, 35(7), 859-869.

Merriam, S. (1997). Qualitative Research and Case Study Applications in Education: Revised and Expanded from Case Study Research in Education. Jossey-Bass.

Merriam, S. B. (1988). Case study research in education: A qualitative approach. San Francisco: Jossey-Bass Publishers.

Meyer, J. W., \& Rowan, B. (1977). Institutionalized organisations: Formal structure as myth and ceremony. American Journal of Sociology, 83(2), 340-363.

Ministry of Higher Education. (2009). Statistics of Higher Education in the KSA, 32. Riyadh: Ministry of Higher Education Press.

Modell, S. (2003). Goals versus institutions: The development of performance measurement in the Swedish university sector. Management Accounting Research, 14(4), 333-359.

NAPCIS. (2012). The History of Accreditation. Retrieved April 15, 2012, from http://www.napcis.org/ history.html

National Commission for Academic Accreditation and Assessment (NCAAA). (2009). Quality Assurance and Accreditation in Saudi Arabia. NCAAA, Riyadh, Saudi Arabia.

National Commission for Academic Accreditation and Assessment (NCAAA). (2010). Quality Assurance and Accreditation in Saudi Arabia. NCAAA, Riyadh, Saudi Arabia.

Oliver, C. (1997). Sustainable Competitive Advantage: Cmbining institutional and resource-based views. Strategic Management Journal, 18, 697-713.

PSU (Prince Sultan University). (2010). Academic Assessment and Planning Center.

PSU (Prince Sultan University). (2011). Strategic Plan, 2011-2016.

PSU (Prince Sultan University). (2013). Learning and Teaching Quality Framework.

PSU (Prince Sultan University). (2013). University Bulletin.

Rosa, M. J., Tavares, D., \& Amaral, A. (2006). Institutional Consequences of Quality Assessment. Quality in Higher Education, 12, 145-159. 
TEQSA. (2013). About TEQSA. Retrieved June 22, 2013, from http://www.teqsa.gov.au/about

University of Aberdeen. (2012). Section 2-Quality Assurance in Higher Education: An Overview. Retrieved April 15, 2012, from http://www.abdn.ac.uk/quality/section2.shtml

Yin, R. (2003). Case study research, design and methods. Newbury Park: Sage Publications.

Zahed, A., Bafail, A., \& Bashir, M. (2007). Quality Assurance of Engineering education at King Abdulaziz University. Proceedings of the 10th UICEE Annual Conference on Engineering Education, Bangkok Thailand, 19-23.

\section{Copyrights}

Copyright for this article is retained by the author(s), with first publication rights granted to the journal.

This is an open-access article distributed under the terms and conditions of the Creative Commons Attribution license (http://creativecommons.org/licenses/by/3.0/). 